\title{
Newborn screening for medium-chain acyl-CoA dehydrogenase deficiency: regional experience and high incidence of carnitine deficiency
}

Maria Luz Couce ${ }^{1 *}$, Paula Sánchez-Pintos ${ }^{1}$, Luisa Diogo ${ }^{2}$, Elisa Leão-Teles ${ }^{3}$, Esmeralda Martins $^{4}$, Helena Santos $^{5}$, Maria Amor Bueno ${ }^{6}$, Carmen Delgado-Pecellín ${ }^{7}$, Daisy E Castiñeiras ${ }^{8}$, José A Cocho ${ }^{8}$, Judit García-Villoria ${ }^{9}$, Antonia Ribes ${ }^{9}$, José M Fraga ${ }^{1}$ and Hugo Rocha ${ }^{10}$

\begin{abstract}
Background: Medium-chain acyl-CoA dehydrogenase deficiency (MCADD) is the most common inherited defect in the mitochondrial fatty acid oxidation pathway, resulting in significant morbidity and mortality in undiagnosed patients.

Newborn screening (NBS) has considerably improved MCADD outcome, but the risk of complication remains in some patients. The aim of this study was to evaluate the relationship between genotype, biochemical parameters and clinical data at diagnosis and during follow-up, in order to optimize monitoring of these patients.
\end{abstract}

Methods: We carried out a multicenter study in southwest Europe, of MCADD patients detected by NBS. Evaluated NBS data included free carnitine (CO) and the acylcarnitines $\mathrm{C} 8, \mathrm{C} 10, \mathrm{C} 10: 1$ together with $\mathrm{C} 8 / \mathrm{C} 2$ and $\mathrm{C} 8 / \mathrm{C} 10$ ratios, clinical presentation parameters and genotype, in 45 patients. Follow-up data included C0 levels, duration of carnitine supplementation and occurrence of metabolic crises.

Results: $C 8 / C 2$ ratio and $C 8$ were the most accurate biomarkers of MCADD in NBS. We found a high number of patients homozygous for the prevalent c.985A > G mutation (75\%). Moreover, in these patients C8, C8/C10 and $\mathrm{C} 8 / \mathrm{C} 2$ were higher than in patients with other genotypes, while median value of C0 was significantly lower (23 $\mu \mathrm{mol} / \mathrm{L}$ vs $36 \mu \mathrm{mol} / \mathrm{L})$.

The average follow-up period was 43 months. To keep carnitine levels within the normal range, carnitine supplementation was required in $82 \%$ of patients, and for a longer period in patients homozygotes for the c.985A>G mutation than in patients with other genotypes (average 31 vs 18 months). Even with treatment, median Co levels remained lower in homozygous patients than in those with other genotypes ( $14 \mu \mathrm{mol} / \mathrm{L}$ vs $22 \mu \mathrm{mol} / \mathrm{L})$. Two patients died and another three suffered a metabolic crisis, all of whom were homozygous for the c.985 A>G mutation.

Conclusions: Our data show a direct association between homozygosity for c.985A>G and lower carnitine values at diagnosis, and a higher dose of carnitine supplementation for maintenance within the normal range. This study contributes to a better understanding of the relationship between genotype and phenotype in newborn patients with MCADD detected through screening which could be useful in improving follow-up strategies and clinical outcome.

Keywords: L-carnitine, Metabolic decompensation, Mitochondrial fatty acid oxidation, Mutations, Newborn screening, Rare disease

\footnotetext{
* Correspondence: maria.luz.couce.pico@sergas.es

'Unidad de Diagnóstico y Tratamiento de Enfermedades Congénitas del Metabolismo, Departamento de Pediatría, Hospital Clínico Universitario, Universidad de Santiago, Santiago de Compostela, Spain

Full list of author information is available at the end of the article
} 


\section{Background}

Medium-chain acyl-CoA dehydrogenase deficiency (MCADD) is the most common inherited fatty acid $\beta$ oxidation (FAO) defect and is a potentially fatal disorder. FAO is a metabolic pathway of particular importance as an energy source during fasting, when glucose supply becomes limited [1]. The overall incidence of MCADD, evaluated by tandem mass spectrometry (MS/MS) newborn screening, is approximately 1:14600, which is 2- to 3-fold higher than the incidence estimated by clinical diagnosis [2]. Incidence varies widely by region, with a higher incidence in the population of northern Europe [3,4].

The MCADD phenotype ranges from asymptomatic [5] to Reye-like syndrome. Typical clinical presentation consists of a metabolic crisis, characterized by hypoketotic hypoglycemia, lethargy, coma [6], seizures or sudden death [7], and triggered by catabolic stress during fasting or illness. The disease usually manifests in the first few years [8], although first presentation in adulthood has also been described [9]. Unusual manifestations, such as neonatal ventricular tachyarrhythmias [10-12], pulmonary haemorrhage [10], and abnormal motor behavior during sleep [13] have also been described. There is a risk of neurological impairment after an acute metabolic decompensation $[8,14]$. The long term follow up of a Dutch cohort of clinically diagnosed cases of MCADD identified disabilities in $21 \%$ of patients [15]. The mortality rate in the first 72 hours of birth is $4 \%$, with and additional mortality rate of $5-7 \%$ by 6 years of age in affected unscreened children $[8,16]$.

Newborn screening (NBS) by MS/MS started in the 1990s. It has since been demonstrated to be accurate and effective [2] with a clear benefit in countries with a high percentage of Caucasians [17], contributing to a reduction in MCADD morbidity and mortality [18]. However, severe metabolic crises still occur, particularly in the early post-natal period prior to NBS $[8,19,20]$ and before screening results are available [12,21]. Patients with fatal neonatal presentation show low residual MCAD enzyme activities $(<1 \%)$ [22].

Elevations of octanoylcarnitine (C8), $\mathrm{C} 8 / \mathrm{C} 10$ and $\mathrm{C} 8 /$ $\mathrm{C} 2$ ratios are the most commonly reported markers in screening for MCADD [23-26]. It is important to bear in mind that $\mathrm{C} 8$ values are likely to be lower when screening samples are collected $72 \mathrm{~h}$ after birth [27]. C8/C10 and $\mathrm{C} 8 / \mathrm{C} 2$ ratios does not seem to be affected by time of sampling [4].

MCAD protein is encoded by the $A C A D M$ gene (OMIM 607008), located on chromosome 1p31. More than 80 mutations have been identified in this gene $\left(\mathrm{HGMD}^{\circ}\right)$, most of which are missense mutations. While screening programs have greatly improved clinical outcome and contributed to current understanding of MCADD, several questions remain. Two of the most important of these are how genotype and phenotype are related $[3,25,28]$ and the clinical relevance of novel variants of $A C A D M$, as identified by newborn screening. Approximately $80 \%$ of patients diagnosed clinically are homozygous for the common c.985A>G mutation [25,29]. Patients diagnosed as a result of screening show a different mutational spectrum, with a lower proportion (30-71\%) of homozygotes for the common mutation [3,20,21,23,25,27,30-35]. This diagnosis-dependent difference in frequency of the homozygous c. $985 \mathrm{~A}>\mathrm{G} \mathrm{mu-}$ tation could be due to the increased detection of milder biochemical phenotypes by newborn screening, with a relatively low risk of developing clinical disease, and associated to mutations found only in screened populations $[4,31,36]$. Notably, residual MCAD activity is significantly lower in patients with the common mutation (range 0-8\%), compared to those with other variants (range 0-63\%) [22].

Although most reports indicate that patients homozygous for the most common mutation have a poorer outcome $[2,37,38]$, some homozygous patients who were asymptomatic until adulthood were also reported $[4,8,38,39]$.

The main goal of the present study was to evaluate any relationships between biochemical findings at diagnosis, genotype, free carnitine ( $\mathrm{C} 0$ ) levels during followup, and clinical outcome, in patients with MCADD detected by NBS.

\section{Methods}

\section{Study population}

The present study population comprised MCADD patients diagnosed by two of the Spanish regional (Galicia and western Andalusia) and one Portuguese (north/central) NBS programs. From the initiation of newborn screening by MS/MS in each region (in Galicia in 2000, in Andalusia in 2009, and in Portugal in 2004) until December 2011, the total number of MCADD cases detected were, 13 in Galicia (incidence 1:18736), 8 in Andalusia (incidence 1:23656) and 28 in north/central Portugal (incidence 1:11799). Global frequency is 1:15575. Four cases lacking sufficient genetic or followup data were excluded. The final ethnic breakdown was 31 Gypsy and 14 Caucasian patients.

At diagnosis, the following parameters were evaluated: age at which analytical samples were taken for NBS, presence or absence of clinical symptoms, $\mathrm{C} 0$, medium chain acylcarnitines $(\mathrm{C} 8, \mathrm{C} 6, \mathrm{C} 10, \mathrm{C} 10: 1)$ and ratios of $\mathrm{C} 8 / \mathrm{C} 2$ and $\mathrm{C} 8 / \mathrm{C} 10$ on the NBS blotter. Diagnosis was confirmed by mutation analysis of the $A C A D M$ gene. Clinical course was subsequently monitored.

During follow-up patients received a normal diet, according to age and avoiding prolonged fasting and lipolysis. A daily intake of $1-2 \mathrm{~g} / \mathrm{kg}$ of slow absorption 
carbohydrates was recommended from eight months of age. During any acute intercurrent illness the treatment protocol was: careful management with frequent administration of drinks containing an appropriate amount of glucose until the patient improved. In case of vomiting or clinical deterioration, an urgent hospital admission for intravenous glucose infusion was recommended. Biochemical follow-up included measurement of $\mathrm{C} 0$ in blood spot/plasma at each visit (average frequency of 3 months) and an annual determination of general biochemical parameters including transaminase levels. Few data exist on the consequences of low carnitine in MCADD; supplementation was prescribed if $\mathrm{C} 0$ fell below $12 \mu \mathrm{mol} / \mathrm{L}$ in blood spots or below $20 \mu \mathrm{mol} / \mathrm{L}$ in plasma. Supplementation was only stopped after 2 independent determinations showed free carnitine higher than $\mu \mathrm{mol} / \mathrm{L}$ in blood spots or $20 \mu \mathrm{mol} / \mathrm{L}$ in plasma. Carnitine was reintroduced if it fell again below the control values.

Informed consent was obtained from the parents of all patients. The study was approved by the Ethics Committee of each Hospital. Institutional Review Board: Fundación Ramón Dominguez G 15796683. Address: Travesía da Choupana s/n. 15706 Santiago de Compostela, A Coruña. Spain.

\section{Analytical methods \\ NBS}

Acylcarnitines in blood spots were studied by the standard method of butylation and analysis by MS/MS. MCADD was suspected in a newborn if the medium chain acylcarnitines and/or $\mathrm{C} 8 / \mathrm{C} 2$ or $\mathrm{C} 8 / \mathrm{C} 10$ ratios were higher than the 99.9th percentile of the specific medium acylcarnitine (C8) and/or the ratios $\mathrm{C} 8 / \mathrm{C} 2$ or $\mathrm{C} 8 / \mathrm{C} 10$ (C8 p99.9 $=0.52 \mu \mathrm{M} ; \mathrm{C} 8 / \mathrm{C} 2$ p99.9 = 0.02; C8/C10 p99.9 = 1.8).

\section{Molecular testing}

DNA was isolated and sequenced by standard procedures for blood samples of all patients and their parents, except for two patients conceived by in vitro fertilization with oocyte donation (Patients 1 and 16, Additional file 1 ), and whose biological mothers were not available for analysis. Molecular analysis of $A C A D M$ was performed using standard procedures. Primers were designed to overlap the coding sequences and their flanking regions (sequences available on request). PCR products were purified by ExoSap (usb ${ }^{\circ}$ ) enzyme and sequenced using a Big Dye Terminator Cycler Sequencing Ready reaction kit and the manufacturer's protocol (Applied Biosystems). The sequencing reactions were performed in an $\mathrm{ABI}$ 3130XL Genetic Analyser.

\section{Biochemical follow-up}

C0 was evaluated in blood spots or plasma samples. When using blood spots it was measured by MS/MS, according to the method of Zytkovicz et al [27]. In plasma, C0 was measured by the classical enzymatic/ spectrophotometric assay [40].

When appropriate, data were statistically analyzed using the Student's t-test (with $\mathrm{p}<0.05$ taken to indicate significance).

\section{Results}

During the study period we evaluated 45 patients with MCADD detected by NBS, with the following geographical distribution: 26 cases from Portugal, 13 from Galicia, and 6 from Andalusia. The average age of analytical sample collection during screening was 7 days (range: 035 ), with a median of 5 days and a mode of 4 days. In $82.2 \%$ cases samples were obtained during the first week of life (37/45). In the remaining 8 cases (17.8\%) repeat samples were analyzed subsequently, due to invalidity of the first sample. At diagnosis, all patients were asymptomatic with increased levels of medium chain acylcarnitines.

As shown in Additional file 1, all but patient 39 exhibited a marked elevation of C8 (average $4.8 \pm 4.1 \mu \mathrm{mol} / \mathrm{L}$; $\mathrm{CV}<0.52)$. On the fourth day of postnatal age, patient 39 had a C8 value between percentiles $99.5(0.37 \mu \mathrm{M})$ and $99.9(0.52 \mu \mathrm{M})$, but a higher than normal C8/C2 ratio (0.04). A repeat sample, taken at 23 days of age showed a slight increase in $\mathrm{C} 8(0.54 \mu \mathrm{M})$ and $\mathrm{C} 8 / \mathrm{C} 2$ (0.05), justifying a genetic study. The $\mathrm{C} 8 / \mathrm{C} 2$ ratio was highly increased in all patients, with an average value of $0.28 \pm 0.21 \quad(\mathrm{CV}<0.02)$. A similar tendency was observed with the $\mathrm{C} 8 / \mathrm{C} 10$ ratio, with an average value of $9.8 \pm 5.7 \mu \mathrm{mol} / \mathrm{L}(\mathrm{CV}<1.85)$, but in patients 35 and 39 this ratio was normal $(\mathrm{C} 8 / \mathrm{C} 10=1.6$ and 1$)$. On resampling this ratio increased slightly $(\mathrm{C} 8 / \mathrm{C} 10=1.81)$. Increased levels of $\mathrm{C} 10$ or $\mathrm{C} 10: 1$ was seen in nineteen and thirty nine patients respectively.

A diagnosis of MCADD was confirmed by molecular testing in all patients; 34 patients were homozygous for the prevalent c.985A $>$ G (p.Lys329Glu) mutation and 10 patients were compound heterozygous for the prevalent and another mutation. Only patient 45 did not carry the c. $985 \mathrm{~A}>\mathrm{G}$ mutation in any of the alleles (Additional file 1). Three of the mutations detected, c.600G $>T$ (p.Trp200Cys), c.245G>C (p.Trp82Ser) and c.542A>G (p.Asp181Gly), are novel. Among our screened cases the prevalence of the common mutation was $86 \%$ (78 out of 90 alleles).

Levels of $\mathrm{C} 8$ and ratios of $\mathrm{C} 8 / \mathrm{C} 10$ and $\mathrm{C} 8 / \mathrm{C} 2$ were significantly higher $(\mathrm{p}=0.016)$, while $\mathrm{C} 0$ was significantly lower $(\mathrm{p}<0.001)$ in patients who were homozygous for the prevalent c.985A $>\mathrm{G}$ mutation, compared to with those with other genotypes (Additional file 1).

After diagnosis, all patients received dietary recommendations, but supplementation with L-carnitine $(20-60 \mathrm{mg} /$ $\mathrm{kg} /$ day) was prescribed only to thirty-two patients, having a low $\mathrm{C} 0$. 
The average follow-up period was 3 years and 7 months (range 2 months-10 years 7 months). Follow-up data were available in 39 out of 45 cases (28 homozygous for the c. $985 \mathrm{~A}>\mathrm{G}$ mutation and 11 with other genotypes). Eightytwo percent of patients (32/39) were given carnitine supplementation. Carnitine was not administered to 6 patients as their levels were consistently within the control range. One patient did not receive supplementation because his parents declined treatment, despite fulfilling the biochemical indication as per our protocol. Following carnitine treatment, the average $\mathrm{CO}$ levels were significantly lower in patients homozygous for the common mutation than in patients with other mutations $(14 \mu \mathrm{mol} / \mathrm{L}$ vs $22 \mu \mathrm{mol} / \mathrm{L}, \mathrm{p}<0.001$ ) (Additional file 1). Among the 28 cases homozygous for the c.985A>G mutation, 26 (92.8\%) required L-carnitine supplementation to reach normal levels, while fewer patients with other genotypes needed supplementation $(6 / 11 ; 54.5 \%)$. The average follow-up period for homozygous patients was 31 months while the average for other patients was 18 months. According to our protocol, carnitine supplementation could never be stopped in eleven homozygous patients (34.3\%). Supplementation was stopped in 15 homozygous patients but, reintroduction was necessary in 11 patients. Among 11 patients with a genotype other than homozygosity for the common mutation, carnitine supplementation was only required in one of them continuously (9.1\%).

Two patients of Gypsy ethnicity (patients 4 and 33; Additional file 1) died at 15 and 32 months of age, respectively. Despite frequent carnitine supplementation, patient 4 consistently showed low C0 levels (average 10 $\mu \mathrm{M})$. This patient died in a hospital not participating in the study, due to a lower respiratory tract infection. Patient 33 frequently showed low C0 levels (average 11.5 $\mu \mathrm{M})$, but supplementation of carnitine was not always complied with. This patient died after presenting with gastroenteritis, decreased consciousness, hypotonia and in cardiorespiratory arrest.

Another three (patients 13, 17 and 21, Additional file 1), also of Gypsy ethnicity, suffered metabolic crises with episodes of hypoglycaemia and vomiting, triggered by infection. The remaining patients never had a metabolic crisis, although one (patient 31, Additional file 1) was also diagnosed with maple syrup urine disease.

\section{Discussion}

C8 levels and several other ratios are utilized in screening for MCADD. We analysed the $\mathrm{C} 8, \mathrm{C} 8 / \mathrm{C} 2$ and $\mathrm{C} 8 / \mathrm{C} 10$ in our study and found $\mathrm{C} 8 / \mathrm{C} 2$ ratio to be more accurate than either $\mathrm{C} 8$ and $\mathrm{C} 8 / \mathrm{C} 10$, as it was elevated in all patients. By comparison, C8 was elevated in 44/45 and C8/C10 in 43/ 45 patients. We therefore consider the calculation of $\mathrm{C} 8$ / $\mathrm{C} 2$ ration very important in screening for MCADD. This was exemplified in patients 35 and 39 whose diagnosis could easily have been missed without referral to the $\mathrm{C} 8$ / $\mathrm{C} 2$ ratio. Both these patients were compound heterozygous for the common c.985A $>\mathrm{G}$ mutation as well as for other reported pathogenic mutations (c.683C $>\mathrm{A}$ [41] and c.199T $>C$ [3]), respectively. It is thought that these latter two mutations might confer a more attenuated biochemical phenotype $[3,41]$. Patient 39 presented a biochemical profile similar to MCAD carrier, as also described Hsu et al. [42], and never showed clinical signs. The percentage of cases homozygous for the common mutation (76\%) detected in our cohort was higher than previously reported, ranging from $30 \%$ to $71 \%(47.4 \%$ [3]; $43 \%$ [4]; $53 \%$ [19]; 61\% [21]; 37\% [27]; 71\% [30]; 40\% [31]; 63\% [32]; 36.4\% [33]; 52\% [34]; 30\% [35]). Our results could have a bias due to the high proportion of patients of Gypsy ethnicity $(31 / 45,69 \%)$, in whom the common allele shows a high population frequency [43]; 22/26 (84.6\%) of our patients from Portugal were homozygous for the common mutation, while the remaining 12 homozygous patients were from Spain. We have previously observed that the prevalence for the common mutation in patients from Galicia (north-west Spain) was also high, at 63\% [24].

The higher plasma $\mathrm{C} 8$ levels and $\mathrm{C} 8 / \mathrm{C} 10$ and $\mathrm{C} 8 / \mathrm{C} 2$ ratios that we have found in patients homozygous for the c.985A $>\mathrm{G}$ mutation agree with previous reports $[3,4,20,23,24,34,38,44]$. We noted a statistically significant association between low C0 level at NBS and homozygosity. As shown in Additional file 1, patients homozygous for the common mutation tended to maintain lower levels of $\mathrm{C} 0$ and carnitine supplementation is more frequent necessary in order that the plasma carnitine levels remain within the normal range. Treatment for MCADD is based mainly on diet: avoidance of fasting and ensuring high carbohydrate intake during illness. L-carnitine treatment has been proposed in MCADD therapy [45], although there is as yet no good evidence to support this recommendation. A survey of thirty-one centers in Europe, North America, Asia and Australia showed L-carnitine supplementation in MCADD to be controversial: $36 \%$ of the centers routinely used oral carnitine whereas $32 \%$ used it only in cases of proven carnitine deficiency or intercurrent infection [46]. Bzduch et al [47] reported a homozygous patient who had suffered two Reye-like episodes and whose C0 decreased continuously from an acute crisis for a further 8-13 days but then returned to normal by the $25^{\text {th }}$ day after the episode.

Apart from the c.985A $>\mathrm{G}$ mutation, it is well documented that most of the $A C A D M$ mutations seen in MCADD patients who have been diagnosed as a result of NBS are associated with asymptomatic or moderate clinical forms [48] of the disease. While it is also known that patients with these less commonly seen $A C A D M$ genotypes are also at risk of metabolic decompensation during periods of illness or metabolic stress $[7,43,49,50]$, 
in our cohort clinical symptoms were only manifest in $11 \%$ of patients $(5 / 45)$, all of whom were homozygous for the c. $985 \mathrm{~A}>\mathrm{G}$ mutation.

In conclusion, our study points to that the $A C A D M$ genotype most commonly seen in MCADD might be of particular relevance in refining a follow-up protocol, since plasma carnitine levels in patients homozygous for c. $985 \mathrm{~A}>\mathrm{G}$ tend to be lower and supplementation is required to maintain carnitine within the normal range. Nevertheless, this associations needs to be further supported by future studies with larger patients cohorts. Our results suggest that dietary management should be complemented with close monitoring of $\mathrm{CO}$ levels and carnitine should be supplemented when necessary, and point to that this might be of particularly importance in patients homozygous for the common mutation. By demonstrating an association between carnitine levels and homozygosity for the c.985A>G mutation, the current study also contributes to our understanding of the relationship between genotype/biochemical markers and phenotype in MCADD. To a large extent, however, MCAD deficiency remains unpredictable, indicating the need for further prospective studies.

\section{Additional file}

Additional file 1: Table S1. Summary of levels of acylcarnitines at diagnosis, mutations, carnitine free levels, treatment and evolution of MCADD patients.

\section{Abbreviations}

C10: Decanoylcarnitine (); FAO: Fatty acid $\beta$-oxidation; C0: Free carnitine: MCADD: Medium-chain acyl-CoA dehydrogenase deficiency; NBS: Newborn screening; C8: Octanoylcarnitine; MS/MS: Tandem mass spectrometry.

\section{Competing interests}

None of the authors have any conflict of interest to declare.

\section{Authors' contributions}

MLC, PSP and HR reviewed the literature and conceived the study. LD was involved in patient selection, monitoring and data collection at Coimbra Hospital. ELT was involved in patient selection, monitoring and data collection at S Joao-Porto Hospital. EM was involved in patient selection, monitoring and data collection at María Pía-Porto Hospital. HS was involved in patient selection, monitoring and data collection at Gaia Hospital. MAB and CDP were involved in patient selection, monitoring and data collection at Virgen del Rocío Hospital. DEC and JAC were involved in patient selection, monitoring and data collection at Santiago de Compostela Hospital. JGV and $A R$ interpreted the results of mutation analyses and were involved in the statistical analysis. MLC, AR and JMF reviewed and edited the manuscript. All authors critically revised the manuscript and approved the final version.

\section{Acknowledgements}

We thank all patients and their families for kindly participating in the study.

\section{Author details}

${ }^{1}$ Unidad de Diagnóstico y Tratamiento de Enfermedades Congénitas del Metabolismo, Departamento de Pediatría, Hospital Clínico Universitario, Universidad de Santiago, Santiago de Compostela, Spain. ${ }^{2}$ Centro de Desenvolvimento da Criança Luís Borges, Hospital Pediátrico de Coimbra, Coimbra, Portugal. ${ }^{3}$ Unidade Doenças Metabólicas, Hospital Pediátrico Integrado, Centro Hospitalar de S. João, EPE, Porto, Portugal. ${ }^{4}$ Unidade de
Doenças Metabólicas, Hospital de Crianças Maria Pia, Centro Hospitalar do Porto, Porto, Portugal. 'Departamento de Pediatria, Centro Hospitalar Gaia/ Espinho, Gaia, Portugal. ${ }^{6}$ Unidad de Metabolopatías y Nutrición Infantil, Departamento de Pediatría, Hospital Universitario Virgen del Rocio, Sevilla, Spain. ${ }^{7}$ Departamento de Bioquímica Clínica, Hospital Universitario Virgen del Rocío, Sevilla, Spain. ${ }^{8}$ Unidad de Diagnóstico y Tratamiento de Enfermedades Congénitas del Metabolismo, Laboratorio de Metabolopatías, Hospital Clínico Universitario, Universidad de Santiago, Santiago de Compostela, Spain.

${ }^{9}$ Sección de Errores Congénitos del Metabolismo-IBC, Servicio de Bioquímica y Genética Molecular, Hospital Clínic y Centro de Investigación Biomédica en Red de Enfermedades Raras (CIBERER), Barcelona, Spain. ${ }^{10}$ Unidade de Rastreio Neonatal, Departamento de Genética do Instituto Nacional de Saúde Doutor Ricardo Jorge, Porto, Portugal.

Received: 7 March 2013 Accepted: 5 July 2013

Published: 10 July 2013

\section{References}

1. Houten SM, Wanders RJA: A general introduction to the biochemistry of mitochondrial fatty acid oxidation. J Inherit Metab Dis 2010, 33:469-477.

2. Rhead WJ: Newborn screening for medium-chain acyl-CoA dehydrogenase deficiency: a global perspective. J Inherit Metab Dis 2006, 29:370-377.

3. Maier EM, Liebl B, Röschinger W, Nennstiel-Ratzel U, Fingerhut R, Olgemöller B, Busch U, Krone N, Kries R, Roscher AA: Population spectrum of ACADM genotypes correlated to biochemical phenotypes in newborn screening for medium-chain acyl-CoA dehydrogenase deficiency. Hum Mutat 2005, 25:443-452.

4. Andresen BJ, Lund AM, Hougaard DM, Christensen E, Gahrn B, Christensen M, Bross P, Vested A, Simonsen H, Skogstrand K, Olpin S, Brandt NJ, Skovby F, Nørgaard-Pedersen B, Gregersen N: MCAD deficiency in Denmark. Mol Genet Metab 2012, 106:175-188.

5. Leydiker KB, Neidich JA, Lorey F, Barr EM, Puckett RL, Lobo RM, Abdenur JE: Maternal medium-chain acyl-CoA dehydrogenase deficiency identified by newborn screening. Mol Genet Metab 2011, 103:92-95.

6. Hoflack M, Caruba C, Pitelet G, Hass H, Mas JC, Paquis V, Berard E: Infant coma in the emergency department: 2 cases of MCAD deficiency. Arch Pediatr 2010, 17:1074-1077.

7. Yusupov R, Finegold DN, Naylor EW, Sahai I, Wainsbren S, Levy HL: Sudden death in medium chain acyl-coenzyme a dehydrogenase deficiency (MCADD) despite newborn screening. Mol Genet Metab 2010, 101:33-39.

8. Wilcken B, Haas M, Joy P, Wiley V, Chaplin M, Black C, Fletcher J, McGill J, Boneh $\mathrm{A}$ : Outcome of neonatal screening for medium-chain acyl-CoA dehydrogenase deficiency in Australia: a cohort study. Lancet 2007, 369:37-42.

9. Schatz UA, Ensenauer R: The clinical manifestation of MCAD deficiency: challenges towards adulthood in the screened population. J Inherit Metab Dis 2010, 33:513-520.

10. Maclean K, Rasiah VS, Kirk EPE, Carpenter K, Cooper S, Lui K, Oei J: Pulmonary haemorrhage and cardiac dysfunction in a neonate with medium-chain acyl-CoA dehydrogenase (MCAD) deficiency. Acta Paediatr 2005, 94:114-6.

11. Rice G, Brazelton T, Maginot K, Srinivasan S, Hollman G, Wolff JA: Medium chain acyl-coenzyme A dehydrogenase deficiency in a neonate. $N$ Engl J Med 2007, 357:1781.

12. Yusuf K, Jirapradittha J, Amin HJ, Yu W, Hasan SU: Neonatal ventricular tachyarrhythmias in medium chain acyl-CoA dehydrogenase deficiency. Neonatology 2010, 98:260-264.

13. Meng X, Mao W, Sun W, Li L, Zhan S, Wu X, Huang Z, Zhang X, Ma Y, Wang Y: Sleep induces abnormal motor behaviors caused by medium-chain acylCoA dehydrogenase deficiency: a case report. Sleep Med 2012, 13:115-117.

14. Grosse SD, Khoury MJ, Greene CL, Crider KS, Pollit RJ: The epidemiology of medium chain acyl-CoA dehydrogenase deficiency: an update. Genet Med 2006, 8:205-212.

15. Derks TG, Rejngoud DJ, Waterham HR, Gerver WJ, van den Berg M, Sauer PJ, Smit GP: The natural history of medium-chain acyl CoA dehydrogenase deficiency in The Netherlands: clinical presentation and outcome. J Pediatr 2006, 148:665-70.

16. Wilcken B: Fatty acid oxidation disorders: outcome and long-term prognosis. J Inherit Metab Dis 2010, 33:501-506.

17. Lindner M, Hoffman GF, Matern D: Newborn screening for disorders of fatty-acid oxidation: experience and recommendations from an expert meeting. J Inherit Metab Dis 2010, 33:521-526. 
18. Nennstiel-Ratzel U, Arenz S, Maier EM, Knerr I, Baumkötter J, Röschinger W, Liebl B, Hadorn HB, Roscher AA, von Kries R: Reduced incidence of severe metabolic crisis or death in children with medium chain acyl-CoA dehydrogenase deficiency homozygous for c.985A > G identified by neonatal screening. Mol Genet Metab 2005, 85:157-59.

19. Cyriac J, Venkatesh V, Gupta C: A fatal neonatal presentation of mediumchain acyl coenzyme A dehydrogenase deficiency. J Int Med Res 2008, 36:609-610.

20. Oerton J, Khalid JM, Besley G, Dalton RN, Downing M, Green A, Henderson M, Krywawych S, Leonard J, Andresen BS, Dezateux C: Newborn screening for medium chain acyl-CoA dehydrogenase deficiency in England: prevalence, predictive value and test validity based on 1.5 million screened babies. J Med Screen 2011, 18:173-181.

21. Frazier D, Millington D, McCandless S, Koebert D, Weavil S, Chaing S, Boney A, Moore E, Frazier DM: The tandem mass spectrometry newborn screening experience in North Carolina: 1997-2005. J Inherit Metab Dis 2006, 29:76-85.

22. Touw CM, Smit GP, de Vries M, de Klerk JB, Bosch AM, Visser G, Mulder MF Rubio-Gozalbo ME, Elvers B, Niezen-Koning KE, Wanders RJ, Waterham HR, Reijngoud DJ, Derks TG: Risk stratification by residual enzyme activity after newborn screening for medium-chain acyl-CoA dehydrogenase deficiency: data from a cohort study. Orphanet J Rare Dis 2012, 7:30.

23. Blois B, Riddell C, Dooley K, Dyack S: Newborns with C8 acylcarnitine level over the $90^{\text {th }}$ centile have an increased frequency of the common MCAD 985A > G mutation. J Inherit Metab Dis 2005, 28:551-556.

24. Couce ML, Castiñeiras DE, Moure JD, Cocho JA, Sánchez-Pintos P, GarcíaVilloria J, Quelhas D, Gregersen N, Andresen BS, Ribes A, Fraga JM: Relevance of expanded neonatal screening of medium-chain acyl Co-A dehydrogenase deficiency: outcome of a decade in Galicia (Spain). JIMD Reports 2011, 28:131-136.

25. Arnold GL, Saavedra- Matiz CA, Galvin-Parton PA, Erbe R, DeVicentis E, Kronn D, Mofidi S, Wasserstein M, Pellegrino JE, Levy PA, Adams DJ, Nichols M, Caggana M: Lack of genotype-phenotype correlations and outcome in MCAD deficiency diagnosed by newborn screening in New York State. Mol Genet Metab 2010, 99:263-268.

26. McHugh DM, Cameron CA, Abdenur JE, Abdulrahman M, Adair O, Al Nuaimi SA, Ahlman H, Allen JJ, Antonozzi I, Archer S, et al: Clinical validation of cutoff target ranges in newborn screening of metabolic disorders by tandem mass spectrometry: a worldwide collaborative project. Genet Med 2011, 13:230-254.

27. Zytkovicz TH, Fitzgerald EF, Marsden D, Larson CA, Shih VE, Johnson DM, Strauss AW, Comeau AM, Eaton RB, Grady GF: Tandem mass spectrometric analysis for amino, organic, and fatty acid disorders in newborn dried bloodspots: a two-year summary from the New England Newborn Screening Program. Clin Chem 2001, 47:1945-1955.

28. Gregersen N, Andresen BS, Pedersen CB, Olsen RKJ, Corydon TJ, Bross P: Mitochondrial fatty acid oxidation defects-remaining challenges. J Inherit Metab Dis 2008, 31:643-657.

29. Gregersen N, Winter V, Curtis D, Deufel T, Mack M, Hendrickx J, Willems PJ, Ponzone A, Parrella T, Ponzone R, et al: Medium-chain acyl-CoA dehydrogenase deficiency: the prevalent mutation $\mathrm{G} 985$ is subject to a strong founder effect from northwestern Europe. Hum Heredity 1993, 43:342-50.

30. Yokota I, Coates P, Hale DE, Rinaldo P, Tanaka K: Molecular survey of a prevalent mutation, 985 A-to-G transition, and identification of five infrequent mutations in the medium-chain acyl-CoA dehydrogenase (MCAD) gene in 55 patients with MCAD deficiency. Am J Hum Genet 1991, 49:1280-1291.

31. Derks TG, Boer TS, van Assen A, Bos T, Ruiter J, Waterham HR, NiezenKoning KE, Wanders RJ, Rondeel JM, Loeber JG, Ten Kate LP, Smit GP, Reijngoud DJ: Neonatal screening for medium-chain acyl-CoA dehydrogenase (MCAD) deficiency in The Netherlands: the importance of enzyme analysis to ascertain true MCAD deficiency. J Inherit Metab Dis 2008, 31:88-96.

32. Andresen BS, Dobrowolski SF, O'Reilly L, Muenzer J, McCandless SE, Frazier DM, Udvari S, Bross P, Knudsen I, Banas R, Chace DH, Engel P, Naylor EW, Gregersen N: Medium-chain acyl-CoA dehydrogenase (MCAD) mutations identified by MS/MS-based prospective screening of newborns differ from those observed in patients with clinical symptoms: identification and characterization of a new, prevalent mutation that results in mild MCAD deficiency. Am J Hum Genet 2001, 68:108-118.
33. Carpenter K, Wiley V, Sim K, Heath D, Wilcken B: Evaluation of newborn screening for medium chain acyl-CoA dehydrogenase deficiency in 275000 babies. Arch Dis Child Fetal Neonatal Ed 2001, 85:F105-F109.

34. Kennedy S, Potter BK, Wilson K, Fisher L, Geraghty M, Milburn J, Chakraborty $P$ : The first three years of screening for medium chain acyl-CoA dehydrogenase deficiency (MCADD) by newborn screening Ontario. BMC Pediatr 2010, 10:82.

35. Nichols MJ, Saavedra-Matiz CA, Kenneth AP, Caggana M: Novel mutations causing medium chain acyl-CoA dehydrogenase deficiency: under representation of the common c.985 A > G mutation in the New York State population. Am J Med Genet A 2008, 146A:610-619.

36. Zschocke J, Schulze A, Lindner M, Fiesel S, Olgemöller K, Hoffman GF, Penzien J, Ruiter JP, Wanders RJ, Mayatepek E: Molecular and functional characterization of mild MCAD deficiency. Hum Genet 2001, 108:404-8.

37. Hsu H-W, Zytkovicz TH, Comeau AM, Strauss AW, Marsden D, Shih VE, Grady GF, Eaton RB: Spectrum of medium-chain acyl-CoA dehydrogenase deficiency detected by newborn screening. Pediatrics 2008, 121:108-114.

38. Waddell L, Wiley V, Carpenter K, Bennetts B, Angel L, Andresen BS, Wilcken B: Medium-chain acyl-CoA dehydrogenase deficiency: genotypebiochemical phenotype correlations. Mol Genet Metab 2006, 87:32-39.

39. Duran M, Hofkamp M, Rhead WJ, Saudubray JM, Wadman SK: Sudden child death and "healthy - affected family members with medium-chain acyl-CoA dehydrogenase deficiency. Pediatrics 1986, 78:1052-1057.

40. Wieland $\mathrm{OH}$ : Methods of Enzymatic analysis. In Volume 8. 3rd edition. Edited by Bergmeyer HU. Florida: VCH Verlagsgesellschaft, Weinhiem Deerfield Beach; 1965:481-488.

41. McKinney JT, Longo N, Hahn SH, Matern D, Rinaldo P, Strauss AW, Dobrowolski SF: Rapid, comprehensive screening of the human medium chain acyl-CoA dehydrogenase gene. Mol Genet Metab 2004, 82:112-120.

42. Hsu HW, Zytkovicz TH, Comeau AM, Strauss AW, Marsden D, Shih VE, Grady GF, Eaton RB: Spectrum of medium-chain acyl-CoA dehydrogenase deficiency detected by newborn screening. Pediatrics 2008, 121:e1108-14.

43. Martinez G, Garcia-Lozano JR, Ribes A, Maldonado MD, Baldellou A, de Pablo R, Nuñez-Roldan A: High risk of medium chain acyl-coenzyme A dehydrogenase deficiency among gypsies. Pediatr Res 1998, 44:83-84.

44. Smith EH, Tomas C, McHugh D, Gavrilov D, Raymond K, Rinaldo P, Tortorelli S, Matern D, Highsmith WE, Oglesbee D: Allelic diversity in MCAD deficiency: the biochemical classification of 54 variants identified during 5 years of ACADM sequencing. Mol Genet Metab 2010, 100:241-250.

45. Feillet F, Ogier H, Cheillan D, Aquaviva C, Labarthe F, Baruteau J, Chabrol B, de Lonlay P, Valayanopoulos V, Garnotel R, Dobbelaere D, Briand G, Jeannesson E, Vassault A, Vianey-Saban C: SFEIM: Medium-chain acyl-CoA -dehydrogenase (MCAD) deficiency: French consensus for neonatal screening, diagnosis, and management. Arch Pediatr 2012, 19:184-193.

46. Walter JH: L-carnitine in inborn errors of metabolism: what is the evidence? J Inherit Metab Dis 2003, 26:181-188.

47. Bzduch V, Behulova D, Salingova A, Ponec J, Fabriciova K, Kozak L: Serum free carnitine in medium chain acyl-CoA dehydrogenase deficiency. Bratisl Lek Listy 2003, 104:405-407.

48. Maier EM, Pongratz J, Muntau AC, Liebl B, Nennstiel-Ratzel U, Busch U, Fingerhut R, Olgemöller B, Roscher AA, Röschinger W: Dissection of biochemical borderline phenotypes in carriers and genetic variants of medium-chain acyl-CoA dehyrogenase deficiency: implications for newborn screening [corrected]. Clin Genet 2010, 77:304.

49. Purevsuren J, Kobayashi H, Hasegawa Y, Mushimoto Y, Li H, Fukuda S, Shigematsu Y, Fukao T, Yamaguchi S: A novel molecular aspect of Japanese patients with medium-chain acyl-CoA dehydrogenase deficiency (MCADD): c.449-452delCTGA is a common mutation in Japanese patients with MCADD. Mol Genet Metab 2009, 96:77-79.

50. Thodi G, Georgiou V, Molou E, Loukas YL, Dotsikas Y, Biti S, Papadopoulos K, Doulgerakis E: Characterization of the molecular spectrum of MediumChain Acyl-CoA Dehydrogenase Deficiency in a Greek newborns cohort: Identification of a novel variant. Clin Biochem 2012, 45:116-1172.

doi:10.1186/1750-1172-8-102

Cite this article as: Couce et al:: Newborn screening for medium-chain acyl-CoA dehydrogenase deficiency: regional experience and high incidence of carnitine deficiency. Orphanet Journal of Rare Diseases 2013 8:102 